\title{
Hot flushes, hormone therapy and alternative treatments: 30 years of experience from Sweden
}

\author{
Lotta Lindh-Åstrand, Mikael Hoffmann, Mats Hammar and Anna-Clara Spetz
}

\section{Linköping University Post Print}

\section{Tweet}

N.B.: When citing this work, cite the original article.

Original Publication:

Lotta Lindh-Åstrand, Mikael Hoffmann, Mats Hammar and Anna-Clara Spetz, Hot flushes, hormone therapy and alternative treatments: 30 years of experience from Sweden, 2015, Climacteric, (18), 1, 53-62.

http://dx.doi.org/10.3109/13697137.2014.915516

Copyright: Informa Healthcare

http://informahealthcare.com/

Postprint available at: Linköping University Electronic Press

http://urn.kb.se/resolve?urn=urn:nbn:se:liu:diva-114411 


\section{Hot flushes, Hormone Therapy and alternative treatments:}

30 years of experience from Sweden.

Lotta Lindh-Åstrand* PhD, RN, Mikael Hoffmann** MD, PhD, Mats Hammar* MD, PhD and Anna-Clara Spetz Holm*, MD, PhD,

*Division of Obstetrics and Gynaecology, Department of Clinical and Experimental

Medicine, Faculty of Health Sciences, Linköping University, Department of Obstetrics and Gynaecology in Linköping, County Council of Östergötland, Linköping, Sweden.

** The NEPI foundation, Division of Health Care Analysis, Department of Medicine and Health, Linköping University, Linköping, Sweden.

Short title: Use of Hormone therapy

Key words: Hot flushes, hormone therapy, complementary therapies, cross-sectional study, pharmacoepidemiology

Reprint requests and correspondence:

Anna-Clara Spetz Holm, Department of Clinical and Experimental Medicine, Obstetrics and Gynecology, Faculty of Health Sciences, University Hospital, S-581 85 Linköping, Sweden. e-mail: Anna-Clara.Spetz.Holm@liu.se

Phone: +461010331 30, Fax: +4613148156 


\begin{abstract}
Objectives The use of hormone therapy (HT) for hot flushes has changed dramatically over the past five decades.

In this cross-sectional questionnaire study, the aim was to describe the use of HT and alternative treatments and to study the frequency of hot flushes. A further aim was to compare data from the present questionnaire with data from previous studies made in the same geographic area.
\end{abstract}

Method A questionnaire was sent to a random sample of 2,000 women aged 47-56 years living in Östergötland County, Sweden. The results were compared with findings from previous studies regarding use of HT, alternative treatment and hot flushes, and the number of HT prescriptions dispensed during the corresponding time using data derived from the Swedish Prescribed Drug Registry.

Results The response rate was $66 \%$. Six percent used HT, in line with prevalence data from the Swedish Prescribed Drug Registry. Alternative treatments were used by $10 \%$. About $70 \%$ of postmenopausal women reported flushes and almost one third of those with flushes stated that they would be positive to HT if therapy could be shown to be harmless, a view more often stated by women with severe complaints of hot flushes (67\%).

Conclusion The use of HT and alternative treatments is low and many women suffer from flushes that could be treated. Women considered their knowledge of the climacteric period and treatment options as insufficient. Individualized information should be given and women with significant climacteric complaints, without contraindications, should be given the opportunity to try HT. 


\section{Introduction}

In Sweden, between one half and two thirds of women report hot flushes (HF) around the time of menopause $(1,2)$. Hot flushes and night sweats often cause discomfort and may negatively impact quality of life $(3,4)$. The gold standard for treating HF is hormone therapy (HT) (5), which reduces the flushes by $75 \%$ (6). The use of HT has changed dramatically over the past 50 years. Results from several observational studies reported beneficial effects of long-term HT use leading to subsequent increased use (7-9). Then findings from the WHI- (10), HERS(11) and MWS-studies (12) showed that HT had neither primary (10) nor secondary (11) preventive effects on cardiovascular disease and that the breast cancer risk was increased more than previously expected (12) during long-term use of HT. This led to changed recommendations and decreased use of HT.

Since 2002, new studies, some based on re-analyses of HERS and WHI, have shown that HT probably is safe when used by healthy women for a limited number of years around menopause $(13,14)$. Alternative treatments for HF including clonidine, selective serotonin reuptake inhibitors (SSRIs), relaxation therapies, and acupuncture have been associated with decreased HF in menopausal women, both with and without breast cancer (15-17). However, none of these treatment alternatives seem to be as effective as HT (18-20). Observational studies have shown that postmenopausal women who exercise regularly have a lower occurrence of flushes $(21,22)$ but prospective studies have not yet shown evidence $(23)$. It seems that middle-aged women have limited knowledge about the menopausal transition and HT $(24,25)$, which makes it difficult for them to evaluate the alternative choices of treatment.

The objectives of this study consisted of two parts; 
The aim of part I was to describe the use of HT over the last decade in Sweden, particularly in Östergötland County and the municipality of Linköping, in women undergoing the menopausal transition.

In part II the aim was to analyse the data on HF and the use of HT and alternative treatments in Linköping and Östergötland collected by means of a questionnaire sent in 2010 to women aged 47-56. The questionnaire also included questions about the women's knowledge of the climacteric period and HT. In addition, the aim was to compare data from this questionnaire with data from previous studies made in the same geographic area. 


\section{Material and Methods:}

\section{Part I}

\section{Data from the Swedish Prescribed Drug Registry}

The Swedish Prescribed Drug Registry at the National Board of Health and Welfare contains information on all prescribed drugs dispensed at pharmacies in Sweden (26). It was established in 1999 and since July 2005 the full personal identification number has been included for every entry. The registry covers the entire population in the country (full patient identity data are missing for $<0.3 \%$ of the total amount of dispensed drugs measured in defined daily doses (DDD)).

DDD is the assumed average maintenance dose per day for a drug used for its main indication in adults and is assigned to every drug by the WHO Collaborating Centre for Drug Statistics Methodology, Norway. For every single dispensation the amount of drugs dispensed measured in DDD is registered in the Swedish Prescribed Drug Registry based on the last available DDD-definition at the time of data-extraction $(27,28)$. Aggregated volumes of dispensed drugs are routinely calculated by the National Board of Health and Welfare as DDD per 1,000 women and year for each geographic area, based on mid-annual figures from the national census provided by Statistics Sweden.

Data were extracted for the country as a whole, the county of Östergötland and the municipality of Linköping. The county has a population of almost 430,000 inhabitants with 150,000 residing in Linköping.

Drugs for hormone treatment of climacteric disorder were defined as per oral and transdermal products within G03CA03 estradiol (excluding low dose products and drugs for local treatment); G03CA57 conjugated estrogens; G03CX01 tibolone; G03FA01 norethisterone and estrogen, fixed; G03FA12 medroxyprogesterone and estrogen, fixed; G03FA17 drospirenone and estrogen, G03FB05 norethisterone and estrogen, sequential; G03FB06 
medroxyprogesterone and estrogen, sequential; G03FB09 levonorgestrel and estrogen, sequential; and G03FB11 trimegestone and estrogen, sequential.

\section{Part II}

\section{Cross-sectional study performed in 2010}

A questionnaire included questions regarding demography, climacteric symptoms, menopausal status, HF, vaginal dryness, HT-use, use of alternative treatments, and questions regarding treatment needs, among other questions. The questionnaire was sent in 2010 to a random sample of 2,000 women (200 women in every age group from 47 to 56 years) living

in the county of Östergötland, Sweden. Names and addresses were extracted from the national population registry. A cover letter was included with information about the aim of the study and emphasized that participation was voluntary.

The women were asked to report the frequency of HF during the preceding two weeks. The response choices were: "no flushes", "yes, flushes at least a few times during the last two weeks", "yes, flushes a few times per week" and "yes, daily flushes". The response choices concerning the severity of HF were: "no bother", "mildly bothered"; i.e. feeling of warmth but not associated with sweating and not interrupting the current activity, "moderately bothered"; i.e. feeling of warmth combined with sweating, but not interrupting the current activity and "severely bothered"; i.e. as being more bothered when the activity is interrupted, for example by opening a window, drinking something cold, readjusting clothing, waking up during the night.

The questionnaire was modified from previously used and validated questionnaires developed by us (29-31). To test comprehension, six women, 47-56 years old, were asked to answer the questionnaire in writing. These women were thereafter personally interviewed, after which the questionnaire was modified in order to make it easier to understand. To evaluate the test-retest stability (reproducibility) the questionnaire was sent to 20 women aged between 47 and 56 
years of age. After two weeks the same women, without knowing beforehand, were sent the same questionnaire and asked to answer it again. We analyzed the test-retest stability for 15 questions about demography, menopausal status, vaginal complaints and treatment alternatives for HF. The questions were answered twice by 19 of the 20 women (totally 285 duplicate questions), and $95 \%$ of the questions were answered identically the first and second time.

The questionnaires were coded, which enabled us to send a reminder to women who had not answered within three weeks. After the questionnaires were decoded, the data were optically scanned. Optical scanning was checked manually and not until the first 10 questionnaires had shown total agreement between optical and manual reading was the procedure accepted.

Results from previous studies made in the same area on postmenopausal women.

Between 1982-2003 five studies (1, 30, 32-34) have been performed on menopausal and postmenopausal women in groups ranging in size from 1,118 to 1,867 subjects, aged 52-65, living in the municipality of Linköping, Sweden. Data from these studies concerning HF and HT-use were compared with data from the current questionnaire.

\section{Statistics}

Optically scanned data were exported and analysed by Statistica version 10, Stat Soft Inc for Windows. Descriptive statistical methods were used such as frequency tables and crosstabulation. To test differences between groups Pearsons $\chi^{2}$ test was used, $\mathrm{p}<0.05$ was considered significant. 
The frequency of answered questions varied within the questionnaire and the actual frequency of answers for each question is reported. Missing data for each variable was handled as lost data.

\section{Ethics}

All questionnaire data were handled confidentially. A letter enclosed with the questionnaire informed the women about the study. By answering the questionnaire the women gave consent to participate in the study. Data from the Swedish Prescribed Drug Register were extracted and aggregated by the National Board of Health and Welfare in order to ensure full anonymity. The study protocol was approved by the Regional Ethical Review Board in Linköping, Sweden, D-nr 2010/279-31. 


\section{Results:}

\section{Part I}

Data from the Swedish Drug Registry showed that the amount of HT dispensed decreased from 236 DDD per 1,000 women and day in Östergötland (256 in Sweden) in 2000 to 41 DDD (45 in Sweden) in 2012. The period prevalence per year could only be studied in the Swedish Prescribed Drug Registry from 2006 onward. It decreased from 75 women per 1,000 women in Östergötland in 2006 (87 in Sweden, 73 in Linköping) to 52 in 2012 (58 in Sweden, 52 in Linköping), see figure 1 (data from Linköping not shown).

\section{Part II}

\section{General results:}

After one reminder and exclusion of uncompleted questionnaires the response rate was $66.1 \%$ (Figure 2). Demographic data on the 1,314 eligible women are presented in table 1. In the whole study group $(\mathrm{n}=1,314), 6.7 \%(\mathrm{n}=88)$ of the women were reported as having had hysterectomies and $1.7 \%(\mathrm{n}=22)$ reported as having had bilateral oophorectomy. Seventy-two women (5.5\%) were HT-users. Alternative treatments for HF such as dietary supplements and herbal remedies were used by $10.1 \%(n=78)$ of the 718 women who answered this question. Use of other alternative treatments (one or a combination of acupuncture, exercise, mindfulness, relaxation, changes in food-habits and/or other lifestyle changes) was reported by $22 \%(n=160)$ of the 726 who answered the question. Acupuncture for HF was reported by $0.6 \%$.

\section{Menopausal status}

It was not possible to classify the menopausal status of women who reported use of HT or hormonal contraception, including use of a hormonal intrauterine device. After exclusion of these women, 1,004 women remained. Premenopausal status, i.e. a natural regular menstruation cycle, was reported by 285 (28.4\%) of these 1,004 women. Perimenopausal 
women, defined as those who had an irregular bleeding pattern and the most recent bleeding less than 12 months earlier, constituted $18.1 \%(\mathrm{n}=182)$. More than half of the women, $53.5 \%$ $(n=537)$ were postmenopausal, i.e. reported spontaneous menopause and no bleeding in the preceding 12 months.

\section{Hot flushes}

In women not using HT ( $n=1,229$; missing $n=13)$ HF were reported by $51 \%(n=627)$. Thirtyfour percent $(n=423)$ reported HF on some occasions each week and 17\% $(n=204)$ reported daily HF. The prevalence of HF was highest in the oldest age group $(\mathrm{p}<0.001)$. About half of the women who had any HF and were not using HT reported moderate severity of HF $(n=307 / 627) ; 18.7 \%(n=117 / 627)$ reported severe complaints and about one third had mild complaints $(n=205 / 627)$.

About one fourth of the women who had HF $(n=157)$ reported that they had sought advice due to symptoms related to the climacteric period. Women with moderate HF were more inclined to seek help (47\%) than women with severe HF $(33 \%)(\mathrm{p}<0.001)$.

More than half of the women (58\%) had seen a gynaecologist because of the HF, $22 \%$ had sought help at pharmacies or health food stores, and $14 \%$ had seen a primary care physician. HF in postmenopausal women $(n=497$; missing $n=40)$ are shown in figure 3 .

\section{Analyses in postmenopausal women not using $H T$}

Natural remedies, herbs and/or food supplements were used by $8.3 \%(n=28)$ of postmenopausal women with HF not using HT $(n=339)$. Almost one third $(28.2 \%, n=96)$ of these women used alternative treatments (one or a combination of acupuncture, physical activity, relaxation, mindfulness, changes in food-habits and/or other lifestyle changes (table II).

In postmenopausal women who reported severe HF about $60 \%$ stated "need of treatment" for HF compared with $2.9 \%$ in women who reported mild complaints $(\mathrm{p}<0.001)$ (table III). In 
women with severe complaints who stated "need for treatment", the reasons for refraining from any treatment were fear of side effects $(n=14 ; 38 \%)$, had not yet contacted a gynecologist $(n=11 ; 30 \%)$, discontinued because of side effects $(n=6,16 \%)$, and had been advise not to have treatment $(n=6 ; 16 \%)$.

Almost one third ( $n=95)$ of postmenopausal women not using HT stated that they would be positive to HT if therapy were to be considered harmless. This was more often stated by women with severe complaints $(67.2 \%)$ compared to women with moderate $(26 \%)$ and mild (12.5\%) complaints of $\mathrm{HF}(\mathrm{p}<0.001)$.

Knowledge about the climacteric period and potential treatments

Of all the women in this study $(n=1,314), 53 \%$ stated that they thought they had insufficient knowledge of the menopausal transition and treatment options, about the same percentage (54\%) of women with HF and not using HT (n=607). Thirty five percent of the women who used HT (n=69) also said they had insufficient knowledge.

Almost half (49\%) of women who had sought help $(\mathrm{n}=187)$ for climacteric complaints did not think that their knowledge of the menopausal transition and its potential treatment was sufficient.

\section{Data from previous studies}

In the previous studies $(1,30,32-34)$ both perimenopausal and postmenopausal women were included. Hammar et al (1) reported that about half of the women in the study-group were interested in receiving estrogens if the treatment had no side-effects, and even about one fourth of women who had never experienced HF expressed the same view.

$\mathrm{HF}$ are reported at different frequencies in these studies $(1,30,32-34)$ ranging between 13 $61 \%$, depending on age of the women, severity of HF and also on the percentage of women using HT (table IV). Use of HT and natural remedies is also shown in table IV. 
Acupuncture was used for HF by $0.2 \%$ in 1995 (34), $0.1 \%$ in 1999 (30), and 1.1\% in 2003

(30). In the current study the equivalent number was $0.6 \%$. 


\section{Discussion}

In this current study only 5.5\% of women, 47-56 years old in the county of Östergötland, Sweden, used HT in 2010 at the time of responding to the survey (point prevalence). This corresponds well with the period prevalence for 2010 of 57 per 1,000 women (or $5.7 \%$ ) in the same age interval in Östergötland being treated with HT as reported in the Swedish Prescribed Drug Registry.

Interestingly, almost twice as many women in the present study reported use of Complementary and Alternative Medicine (CAM) in order to reduce HF compared to women using HT. In a group of Italian women aged 45-65, almost half had used some kind of treatment for menopausal symptoms during the preceding year. About $10 \%$ of women who had used other remedies also had used HT. It was shown that more than one of four women in this group had used CAM remedies, mostly herbal products and soy, in the diet (35). Women thus seem to be more prone to try natural remedies, herbs and food supplements than to use HT for relief of climacteric problems. It should be emphasized that such treatments have not been very well studied or regulated and studies explicitly designed to find negative long-term effects on, for example, breast-tissue and/or endometrium have not yet been published. Furthermore some species of red clover may interfere with coagulation and may cause herbdrug interactions, although these data are not conclusive (36). In 2006 EMEA published a warning advising against unrestricted use of Black cohosh (37). Recently a meta-analysis of RCT's on black cohosh showed no evidence of hepatotoxicity (38). Since CAM remedies are not regulated as drugs they can be bought over the counter in pharmacies and convenience stores, without prescription and information about adverse effects, which may lead to a false sense of safety (19). 
Perhaps HT-use is still seen as something to be avoided because of the results from WHI(10), HERS- (11) and WMS- (12) studies. This view is supported by our finding that one third of the postmenopausal women not on HT said that they would be positive to HT if there was evidence that the treatment is harmless. An even greater percentage (more than $60 \%$ ) of women with severe complaints took this position. In postmenopausal women with severe HF, six of ten women stated that they needed treatment for flushes, and that the most common reason for not using HT was fear of side effects. Also the more frequent and severe flushes the woman reported; the greater was their expressed need for therapy. We suspect that many women have a fear of HT that is not evidence based, and these women need to be given more individualized and differentiated information. More than half of all women in the study and even one third of women on HT stated that they had insufficient knowledge about the climacteric period and its treatment options. Probably the lack of information and knowledge of HT and its risks and benefits lead the women to try other therapies such as natural remedies, herbs and food supplement since they consider these treatments safer. Recent metaanalyses show positive evidence that phytoestrogens are effective in alleviating menopausal symptoms, but more studies are needed $(39,40)$. According to a systematic review, herbal preparations containing black cohosh cause a reduction in menopausal symptoms by $26 \%$; but there were significant differences between trials (41). However, a Cochrane review from 2012 stated that more studies are needed to support whether the use of black cohosh is effective for hot flushes or not (42).

It appears that more studies are needed both for evaluating the efficacy on HF and also the long-term-safety of these preparations. Other prescribed drugs, such as clonidine, SSRI, and gabapentin decrease the frequency and severity of HF but not as effectively as HT $(18,19)$. The use of these drugs was low among the women who participated in the present study, and is therefore not discussed further. 
In line with previous studies (43-45) the present study showed that almost $70 \%$ of postmenopausal women not on HT reported HF, and more than one third of these had daily complaints. Thus many women report and suffer from HF without seeking medical advice, probably due to fear of side effects from HT. Reanalyses of the WHI suggest that the age of the woman at initiation of therapy is crucial, and when HT is prescribed within 4-6 years of menopause, there are probably cardio- and neuro-protective effects (13). On the other hand a recent study suggests that women with early onset of HT after menopause are at higher risk of breast cancer than women with delayed onset (46). Also, a meta-analysis of 23 randomized, controlled trials showed a significant reduction of cardiac events in women with early menopause using HT (47). Other interesting findings in the risk/benefit evaluation are the possible relation between HF and increased risk of CVD (48). Furthermore, if HT is initiated before the age of 60 , a significant reduction in all-cause mortality is seen compared to mortality in the group on placebo (47). If women were better informed about these results this might lead to a wider acceptance of estrogen therapy in postmenopausal women (49).

One limitation is the response rate, which in our study was slightly lower (66\%) than in earlier studies of women in the same area (at or above $75 \%)(1,32,34,35)$. This decline in response rates is in agreement with a general secular trend in Sweden and is not unique for Swedish studies. The declining response rate will probably decrease the response representativeness of the results, increase the bias of the trend estimates and limit the comparability of the results between population groups and surveys (50).

On the other hand the proportion of HT users in this study was congruent with data from the Swedish Prescribed Drug Registry. This supports the interpretation that women who answered the questionnaire in this study seem to be representative of the whole population. 
In the current study $10.9 \%$ of the responders had a native language other than Swedish. In the same geographical area, $15.5 \%$ of the women in the same age-group were not born in Sweden, according to data from Sweden Statistics. Women born outside Sweden might have had Swedish or one of the closely related Nordic languages as a native language. Our interpretation is that there probably is a lower response rate among immigrants and the overall results may not be used to describe with certainty the situation among this minority group. Data from non-responders could not be collected because of the use of coded questionnaires. We have also various numbers of missing data on single questions, despite a ninety-five percent similarity when we analysed test-retest stability before the survey. We choose to only show the results that are given, i.e. no calculated values for missing data were included, since we consider that the results are more "true" in that way.

In conclusion, $\mathrm{HF}$ are common around menopause and our findings are in line with similar studies $(51,52)$ of menopausal women not on HT. Apparently HT-use is much lower than the prevalence of flushes and many women probably suffer unnecessarily. Women in this study seem to be more prone to use herbal remedies, food supplements and alternative treatments than to use HT. Women with severe complaints from HF stated they would be more likely to request HT if they could be assured that it does not increase the risk of serious disease. Many women have a fear of HT that is no longer justified by the most recent research. We suggest that more individualized and differentiated information should be given to women during the menopausal transition, to counteract their fear of HT, giving women with significant climacteric complaints and without contraindications of HT the possibility to make a wellreasoned decision whether or not to use HT.

Acknowledgement: (Financial support) We are indebted to the Lions Foundation, research grants from the County Council of Östergötland and Linköping University. 


\section{References}

1. Hammar M, Berg G, Fahraeus L, Larsson-Cohn U. Climacteric symptoms in an unselected sample of Swedish women. Maturitas. 1984;6(4):345-50.

2. McKinlay SM, Brambilla DJ, Posner JG. The normal menopause transition. Maturitas. 1992;14(2):103-15.

3. Avis NE, Ory M, Matthews KA, Schocken M, Bromberger J, Colvin A. Healthrelated quality of life in a multiethnic sample of middle-aged women: Study of Women's Health Across the Nation (SWAN). Med Care. 2003;41(11):1262-76.

4. Ledesert B, Ringa V, Breart G. Menopause and perceived health status among the women of the French GAZEL cohort. Maturitas. 1994;20(2-3):113-20.

5. Shen W, Stearns V. Treatment strategies for hot flushes. Expert opinion on pharmacotherapy. 2009;10(7):1133-44.

6. Maclennan AH, Broadbent JL, Lester S, Moore V. Oral oestrogen and combined oestrogen/progestogen therapy versus placebo for hot flushes. Cochrane Database Syst Rev. 2004(4):CD002978.

7. Grodstein F, Stampfer MJ, Colditz GA, Willett WC, Manson JE, Joffe M, et al. Postmenopausal hormone therapy and mortality. N Engl J Med. 1997;336(25):1769-75.

8. Criqui MH, Suarez L, Barrett-Connor E, McPhillips J, Wingard DL, Garland C. Postmenopausal estrogen use and mortality. Results from a prospective study in a defined, homogeneous community. Am J Epidemiol. 1988;128(3):606-14.

9. Birkhauser M. Menopause in the aging society. . In: Takeshi A, Takumi Y, Seiichiro F, editors. The Menopause at the Millenium. NewYork: The Parthenon Publishing Group; 1999. p. 101-7.

10. Rossouw JE, Anderson GL, Prentice RL, LaCroix AZ, Kooperberg C, Stefanick ML, et al. Risks and benefits of estrogen plus progestin in healthy postmenopausal women: 
principal results From the Women's Health Initiative randomized controlled trial. JAMA. 2002;288(3):321-33.

11. Herrington DM, Vittinghoff E, Lin F, Fong J, Harris F, Hunninghake D, et al. Statin therapy, cardiovascular events, and total mortality in the Heart and Estrogen/Progestin Replacement Study (HERS). Circulation. 2002;105(25):2962-7.

12. Beral V. Breast cancer and hormone-replacement therapy in the Million Women Study. Lancet. 2003;362(9382):419-27.

13. Phillips LS, Langer RD. Postmenopausal hormone therapy: critical reappraisal and a unified hypothesis. Fertil Steril. 2005;83(3):558-66.

14. Rossouw JE, Prentice RL, Manson JE, Wu L, Barad D, Barnabei VM, et al. Postmenopausal hormone therapy and risk of cardiovascular disease by age and years since menopause. JAMA. 2007;297(13):1465-77.

15. Nedstrand E, Wijma K, Wyon Y, Hammar M. Vasomotor symptoms decrease in women with breast cancer randomized to treatment with applied relaxation or electroacupuncture: a preliminary study. Climacteric. 2005;8(3):243-50.

16. Cohen SM, Rousseau ME, Carey BL. Can acupuncture ease the symptoms of menopause? Holistic nursing practice. 2003;17(6):295-9.

17. Nir Y, Huang MI, Schnyer R, Chen B, Manber R. Acupuncture for postmenopausal hot flushes. Maturitas. 2007;56(4):383-95.

18. Wong VC, Lim CE, Luo X, Wong WS. Current alternative and complementary therapies used in menopause. Gynecol Endocrinol. 2009;25(3):166-74.

19. Albertazzi P. Non-estrogenic approaches for the treatment of climacteric symptoms. Climacteric. 2007;10 Suppl 2:115-20. 
oral estradiol treatment of vasomotor symptoms in postmenopausal women. Climacteric. 2004;7(2):153-64.

21. Hammar M, Berg G, Lindgren R. Does physical exercise influence the frequency of postmenopausal hot flushes? Acta Obstet Gynecol Scand. 1990;69(5):409-12. 22. Ivarsson T, Spetz AC, Hammar M. Physical exercise and vasomotor symptoms in postmenopausal women. Maturitas. 1998;29(2):139-46.

23. Daley A, Stokes-Lampard H, Macarthur C. Exercise for vasomotor menopausal symptoms. Cochrane Database Syst Rev. 2011(5):CD006108.

24. Lindh-Astrand L, Brynhildsen J, Hoffmann M, Kjellgren KI, Hammar M. Knowledge of reproductive physiology and hormone therapy in 53- to 54-year-old Swedish women: a population-based study. Menopause. 2007;14(6):1039-46.

25. Tao M, Teng Y, Shao H, Wu P, Mills EJ. Knowledge, perceptions and information about hormone therapy (HT) among menopausal women: a systematic review and meta-synthesis. PLoS One. 2011;6(9):e24661.

26. Wettermark B, Hammar N, Fored CM, Leimanis A, Otterblad Olausson P, Bergman U, et al. The new Swedish Prescribed Drug Register--opportunities for pharmacoepidemiological research and experience from the first six months. Pharmacoepidemiology and drug safety. 2007;16(7):726-35.

27. Ronning M, Blix HS, Harbo BT, Strom H. Different versions of the anatomical therapeutic chemical classification system and the defined daily dose--are drug utilisation data comparable? European journal of clinical pharmacology. 2000;56(9-10):723-7.

28. Organization WH. Collaborating Centre for Drug Statistics Methodology 201310-03. Available from: http://www.whocc.no. 
55, 65, and 75 years, living in the community of Linkoping, Sweden. Menopause. 2003;10(1):81-7.

30. Hoffmann M, Hammar M, Kjellgren KI, Lindh-Astrand L, Brynhildsen J. Changes in women's attitudes towards and use of hormone therapy after HERS and WHI. Maturitas. 2005;52(1):11-7.

31. Spetz AC, Palmefors L, Skobe RS, Stromstedt MT, Fredriksson MG, Theodorsson E, et al. Testosterone correlated to symptoms of partial androgen deficiency in aging men (PADAM) in an elderly Swedish population. Menopause. 2007;14(6):999-1005. 32. Berg G, Gottwall T, Hammar M, Lindgren R. Climacteric symptoms among women aged 60-62 in Linkoping, Sweden, in 1986. Maturitas. 1988;10(3):193-9.

33. Lindgren R, Berg G, Hammar M, Zuccon E. Hormonal replacement therapy and sexuality in a population of Swedish postmenopausal women. Acta Obstet Gynecol Scand. $1993 ; 72(4): 292-7$.

34. Hammar M, Brynhildsen J, Dabrosin L, Frisk J, Lindgren R, Nedstrand E, et al. Hormone replacement therapy and previous use of oral contraceptives among Swedish women. Maturitas. 1996;25(3):193-9.

35. Cardini F, Lesi G, Lombardo F, van der Sluijs C, Group MMSC. The use of Complementary and Alternative Medicine by women experiencing menopausal symptoms in Bologna. BMC Womens Health. 2010;10:7.

36. Nachtigall LE, Baber RJ, Barentsen R, Durand N, Panay N, Pitkin J, et al. Complementary and hormonal therapy for vasomotor symptom relief: a conservative clinical approach. Journal of obstetrics and gynaecology Canada : JOGC $=$ Journal d'obstetrique et gynecologie du Canada : JOGC. 2006;28(4):279-89. 
racemosae Rhizoma (Black cohosh, root) - Serious hepatic reactions [press release]. 2006.

38. Naser B, Schnitker J, Minkin MJ, de Arriba SG, Nolte KU, Osmers R. Suspected black cohosh hepatotoxicity: no evidence by meta-analysis of randomized controlled clinical trials for isopropanolic black cohosh extract. Menopause. 2011;18(4):36675.

39. Lethaby A, Marjoribanks J, Kronenberg F, Roberts H, Eden J, Brown J. Phytoestrogens for menopausal vasomotor symptoms. Cochrane Database Syst Rev. 2013;12:CD001395.

40. Bedell S, Nachtigall M, Naftolin F. The pros and cons of plant estrogens for menopause. The Journal of steroid biochemistry and molecular biology. 2014;139:225-36. 41. Shams T, Setia MS, Hemmings R, McCusker J, Sewitch M, Ciampi A. Efficacy of black cohosh-containing preparations on menopausal symptoms: a meta-analysis. Alternative therapies in health and medicine. 2010;16(1):36-44. Leach MJ, Moore V. Black cohosh (Cimicifuga spp.) for menopausal symptoms. Cochrane Database Syst Rev. 2012;9:CD007244.

43. Blumel JE, Chedraui P, Baron G, Belzares E, Bencosme A, Calle A, et al. A large multinational study of vasomotor symptom prevalence, duration, and impact on quality of life in middle-aged women. Menopause. 2011;18(7):778-85.

44. Hunter MS, Gentry-Maharaj A, Ryan A, Burnell M, Lanceley A, Fraser L, et al. Prevalence, frequency and problem rating of hot flushes persist in older postmenopausal women: impact of age, body mass index, hysterectomy, hormone therapy use, lifestyle and mood in a cross-sectional cohort study of 10,418 British women aged 54-65. BJOG. 2012;119(1):40-50. 
45. Freeman EW, Sherif K. Prevalence of hot flushes and night sweats around the world: a systematic review. Climacteric. 2007;10(3):197-214.

46. Cordina-Duverger E, Truong T, Anger A, Sanchez M, Arveux P, Kerbrat P, et al. Risk of breast cancer by type of menopausal hormone therapy: a case-control study among post-menopausal women in France. PLoS One. 2013;8(11):e78016.

47. Salpeter SR, Walsh JM, Greyber E, Ormiston TM, Salpeter EE. Mortality associated with hormone replacement therapy in younger and older women: a meta-analysis. $\mathbf{J}$ Gen Intern Med. 2004;19(7):791-804.

48. Thurston RC, El Khoudary SR, Sutton-Tyrrell K, Crandall CJ, Sternfeld B, Joffe $\mathrm{H}$, et al. Vasomotor symptoms and insulin resistance in the study of women's health across the nation. J Clin Endocrinol Metab. 2012;97(10):3487-94.

49. Sturdee DW, MacLennan AH. The pendulum swings back; estrogen is now beneficial if started at the right time. Climacteric. 2006;9(2):73-4.

50. Tolonen H, Helakorpi S, Talala K, Helasoja V, Martelin T, Prattala R. 25-year trends and socio-demographic differences in response rates: Finnish adult health behaviour survey. European journal of epidemiology. 2006;21(6):409-15.

51. Sprague BL, Trentham-Dietz A, Cronin KA. A sustained decline in postmenopausal hormone use: results from the National Health and Nutrition Examination Survey, 1999-2010. Obstet Gynecol. 2012;120(3):595-603.

52. Ettinger B, Wang SM, Leslie RS, Patel BV, Boulware MJ, Mann ME, et al. Evolution of postmenopausal hormone therapy between 2002 and 2009. Menopause. 2012;19(6):610-5. 


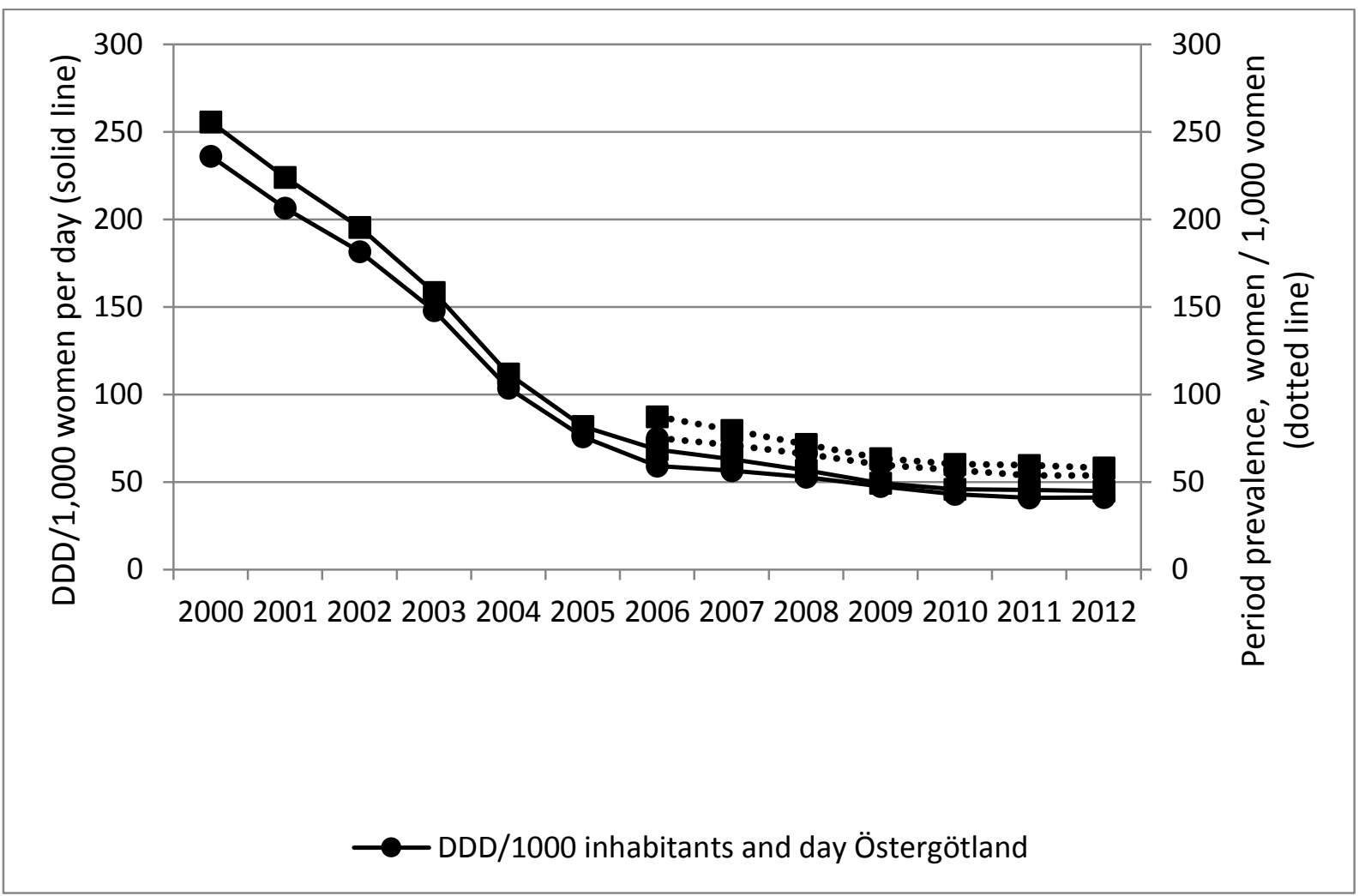

Figure 1: Amount of HT dispensed per year to women 47-56 year in defined daily dose per 1,000 (DDD/1,000) women (solid line) 2000-2012 and period prevalence for HT for women in the same age group (dotted line) 2006-2012. Data for Östergötland (circles) and Sweden (square). 


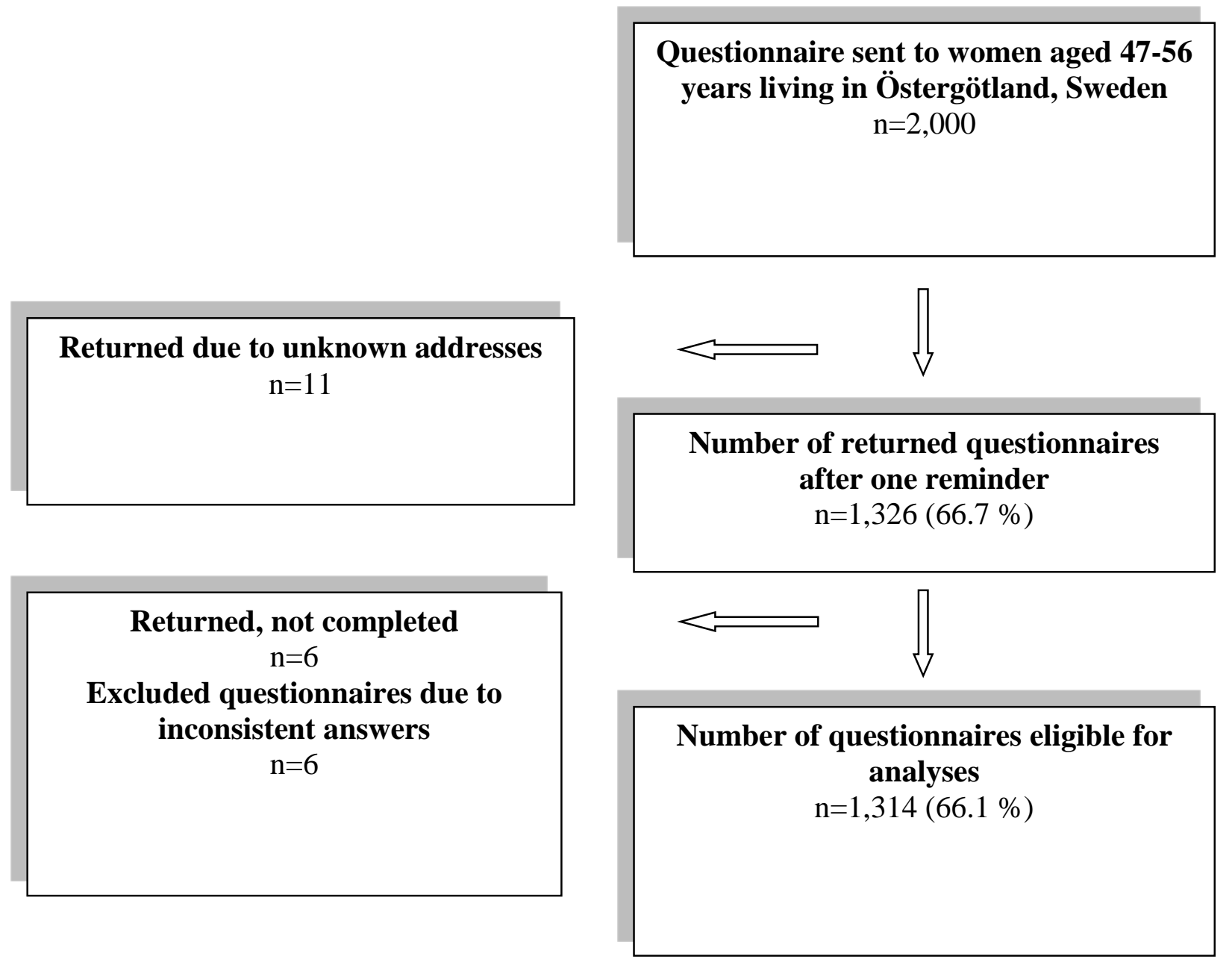

Figure 2: Flow chart showing the response rate of questionnaires 2010. 


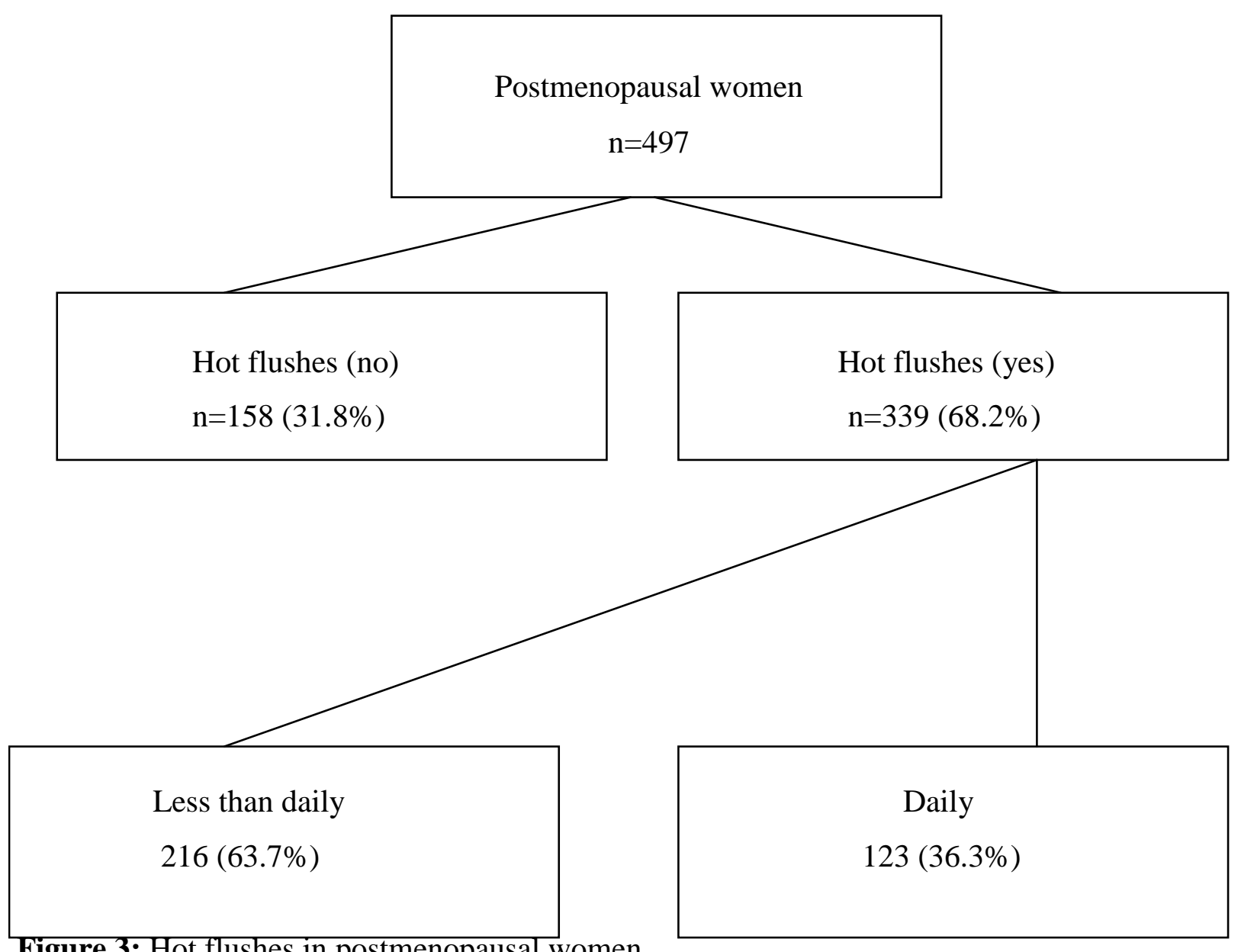

Figure 3: Hot flushes in postmenopausal women. 
Table 1: Characteristics of women answering the questionnaire in $2010(n=1,314)$.

Percentages within brackets, total number of missing answers varied between $0-16$ for the different questions.

\begin{tabular}{llll}
\hline Age group $\left(\mathbf{y}^{*}\right)$ & $\mathbf{4 7 - 4 9}$ & $\mathbf{5 0 - 5 2}$ & $\mathbf{5 3 - 5 6}$ \\
Number of responders & $\mathrm{n}=384$ & $\mathrm{n}=378$ & $\mathrm{n}=552$
\end{tabular}

\section{$\operatorname{BMI}^{\dagger}\left(\mathbf{k g} / \mathbf{m}^{2}\right)$}

$<25$

$211(56.7) \quad 186(50.1) \quad 280(52.2)$

$\geq 25-<30$

$105(28.2)$

$117(31.5)$

$178(33.2)$

$>30$

$56(15.1)$

$68(18.3)$

$78(14.6)$

\section{Smoking habits}

No

$305(79.6) \quad 293(77.7) \quad 434(78.9)$

Yes, sometimes

$26(6.8)$

$28(7.4)$

$29 \quad(5.3)$

Yes, every day

$52(13.6)$

$65(14.9)$

$87(15.8)$

\section{Alcohol habits}

No alcohol

$65(17.0)$

$51(13.6) \quad 91(16.7)$

Some time/month

$164(42.9)$

$165(44.0) \quad 216(39.6)$

Every week

$150(39.3)$

$155(41.3) \quad 231(42.3)$

Every day

$3(0.8)$

$4(1.1)$

$8(1.5)$

\section{Employment status}

Work fulltime

$248(64.8)$

$242(64.5) \quad 359(65.4)$ 
Work part-time

House-wife

Applying for job/studying

Sick-leave/Retired due to disease
$78(20.4)$

$7(1.8)$

$23(6.0)$

$27(7.0)$

\section{Civil status}

Married/cohabiting

Single/divorced

(previously married/cohabiting)

Stable relationship

$20(5.2)$

$22(5.8)$

$17(3.1)$

but living apart

Living alone

\section{Education}

9 years of compulsory schooling 34 (8.9)

High school

$162(42.2)$

$188(49.0)$

University degree

\section{Resident}

Rural residence

$56(14.7)$

$64(17.1) \quad 92(16.9)$

$<50$ inhabitants

Rural residence

89 (23.4)

$>50$ inhabitants
$59(15.7) \quad 105(19.2)$

$159(42.4) \quad 210(38.4)$

$157(41.9) \quad 232(42.4)$
$22(5.9) \quad 47(8.6)$

$7(1.9) \quad 9(1.6)$ 
City residence

$$
63 \text { (16.6) }
$$

$52(13.9)$

$81(14.9)$

$<20000$ inhabitants

City residence

$172(45.3)$

$184(49.1) \quad 260(47.9)$

$>20000$ inhabitants

Native language

Swedish

$333(86.7)$

$334(89.3) \quad 498(90.5)$

Another Scandinavian**

$8(2.1)$

$8(2.1)$

$12(2.2)$

language

Non-Scandinavian

$43(11.2)$

$32(8.6)$

$40(7.3)$

\section{Hysterectomized}

Yes

$24(6.3)$

$29(7.7) \quad 35(6.4)$

No

$359(93.7)$

349 (92.3) $515(93.5)$

Unknown

$0(0.0)$

$0(0.0) \quad 1(0.2)$

\section{Oophorectomized}

Yes

$7(1.8)$

$7(1.9) \quad 8(1.5)$

No

$376(97.9)$

$371(98.2) \quad 539(98.0)$

Unknown

$1(0.3)$

$0(0.0) \quad 3(0.6)$

\section{Daily medication}


Yes

No
$84(22.9) \quad 170(31.9)$

$283(77.1) \quad 363(68.1)$

* Age range of group

$\dagger$ Body Mass Index

** Danish, Norwegian, and Swedish

*Daily medication includes antihypertensive treatment, psychoactive medication and/or thyroid medication 
Table 2: Use of alternative treatments ${ }^{\dagger}$ for hot flushes related to severity of hot flushes in postmenopausal women not using HT ( $n=321$; missing $n=18)$.

Severity of mild moderate missing

hot flushes ${ }^{\ddagger}$ :

Natural remedies, herbs,

food supplements

\begin{tabular}{lllll}
\hline Yes & $8.6 \%(\mathrm{n}=9)$ & $5.2 \%(\mathrm{n}=8)^{*}$ & $18.3 \%(\mathrm{n}=11)^{*}$ & $\mathrm{n}=2$ \\
No & $91.4 \%(\mathrm{n}=96)$ & $94.8 \%(\mathrm{n}=146)^{*}$ & $81.7 \%(\mathrm{n}=49)^{*}$ & $\mathrm{n}=2$
\end{tabular}

Alternative treatments $^{\dagger}$

\begin{tabular}{llllr}
\hline Yes & $21.0 \%(\mathrm{n}=22)$ & $28.6 \%(\mathrm{n}=44)$ & $41.7 \%(\mathrm{n}=25) * *$ & $\mathrm{n}=2$ \\
No & $79.1 \%(\mathrm{n}=83) * *$ & $71.4 \%(\mathrm{n}=110)$ & $58.3 \%(\mathrm{n}=35) * *$ & $\mathrm{n}=2$
\end{tabular}

${ }^{\dagger}$ Alternative treatments=one or a combination of acupuncture, physical activity, relaxation, changes in dietary habits and/or other changes of life-style.

Severity of hot flushes

- Mild: feeling of warmth but no sweating and not interrupting the current activity,

- Moderate; feeling of warmth combined with sweating, but not interrupting the current activity

- Severe; same as moderate but the activity is interrupted, for example by open a window, drink something cold, readjust the clothing, wake up during the night.

$* \mathrm{p}<0.001$ between women with moderate and severe hot flushes

$* * \mathrm{p}<0.01$ between women with mild and severe hot flushes 
Table 3: Frequency and severity" of hot flushes in postmenopausal women who stated "need for treatment" of flushes $(n=339)$. Women on HT $(n=72)$ and women without hot flushes $(n=$ 93) are excluded.

Hot flushes

Need for treatment

No need for treatment

Treatment other

than $\mathrm{HT}^{\dagger}$

Frequency (missing=1)

\begin{tabular}{lccc}
\hline Sometimes or & & & \\
a couple of times/w & $4.6 \%(\mathrm{n}=10)$ & $93.5 \%(\mathrm{n}=202)$ & $1.9 \%(\mathrm{n}=4)$ \\
Flushes every day & $36.9 \%(\mathrm{n}=45)$ & $59.8 \%(\mathrm{n}=73)$ & $3.3 \%(\mathrm{n}=4)$ \\
\hline Severity* (missing=3) & & & \\
\hline Mild & $2.9 \%(\mathrm{n}=3)$ & $95.2 \%(\mathrm{n}=100)$ & $1.9 \%(\mathrm{n}=2)$ \\
Moderate & $9.7 \%(\mathrm{n}=15)$ & $88.4 \%(\mathrm{n}=137)$ & $1.9 \%(\mathrm{n}=3)$ \\
Severe & $61.7 \%(\mathrm{n}=37)$ & $33.3 \%(\mathrm{n}=20)$ & $5.0 \%(\mathrm{n}=3)$ \\
\hline
\end{tabular}

*Severity of hot flushes:

- Mild: feeling of warmth but no sweating and not interrupting the current activity,

- Moderate; feeling of warmth combined with sweating, but not interrupting the current activity

- Severe; same as moderate but the activity is interrupted, for example by open a window, drink something cold, readjust the clothing, wake up during the night.

${ }^{\dagger}$ Have treatment other than HT (not specified) 
Table 4: Hot flushes and reported use of HT from 1982 to 2003 in the municipality of Linköping and the province of Östergötland, Sweden.

\begin{tabular}{|c|c|c|c|c|c|c|c|}
\hline Authors & $\begin{array}{l}\text { Year of } \\
\text { survey }\end{array}$ & $\begin{array}{l}\text { Age } \\
\text { (years) }\end{array}$ & $\begin{array}{l}\text { Number } \\
\text { of responders }\end{array}$ & $\begin{array}{l}\text { Response } \\
\text { rate }(\%)\end{array}$ & Hot flushes & HT-user ${ }^{*}$ & $\begin{array}{l}\text { Use of } \\
\text { natural remedies* }\end{array}$ \\
\hline Hammar et al 1984 (1) & 1982 & 52,54 & 1,118 & $90 \%$ & $61 \%$ & $7 \%$ & ---- \\
\hline Berg et al 1988 (32) & 1986 & $60,61,62$ & 1,469 & $73 \%$ & $27 \%$ & $6 \%$ & ---- \\
\hline Lindgren et al 1993 (33) & 1988 & $55,57,59,65$ & 1,867 & $76 \%$ & $52 \%$ & $14 \%^{\dagger}, 4 \%^{* *}$ & ---- \\
\hline Hammar et al 1996 (34) & 1995 & 55,56 & 1,122 & $85 \%$ & $13 \%$ & $35 \%$ & $5 \%$ \\
\hline \multirow[t]{2}{*}{ Hoffmann et al 2005 (30) } & 1999 & 53,54 & 1,180 & $74 \%$ & ---- & $41 \%$ & $2 \%$ \\
\hline & 2003 & 53,54 & 1,263 & $77 \%$ & ---- & $25 \%$ & $6 \%$ \\
\hline The current study & 2010 & $47-56$ & 1,314 & $66 \%$ & $51 \%{ }^{* * *}$ & $6 \%$ & $8 \%^{* * *}$ \\
\hline
\end{tabular}

\footnotetext{
* only current users

$\dagger$ of 55 years old women

** of 65 years old women
} 
${ }^{\ddagger}$ of women having current flushes of moderate to severe degree

*** women using HT excluded 